\title{
Approaches to the diagnosis of the comfort of the living environment in cities
}

\author{
Nina Polyakova ${ }^{1, *}$, and Vitaliy Zaleshin ${ }^{2}$ \\ ${ }^{1}$ Institute of Economics and Management, Baikal State University, 664003, Lenin ave., 11, Irkutsk, \\ Russia \\ ${ }^{2}$ Independent expert, 664003, Irkutsk, Russia
}

\begin{abstract}
The paper is devoted to the substantiation of the approach to diagnosing the comfort of the urban environment from the position of the city marketing theory, namely, based on the management and commodity concept. The latter is characterized by the obligatory consideration of interests and their interconnection of all stakeholders - residents, authorities, business community, etc., and also the focus on solving both tactical and strategic tasks of the city development. An overview of the main approaches and methods for studying the comfort of the urban environment is presented. The comfort of the urban environment determines the level of urban development as a whole. Therefore, it is necessary to treat this concept as a system-forming, and not a particular one, in contrast to the position of many authors. The basis of the proposed approach is a system of criteria that collectively reflect the functional, social and psychological requirements of citizens to the comfort of their living environment.
\end{abstract}

\section{Introduction}

Providing a comfortable living environment is one of the priority goals of urban marketing. Specialists came to this conclusion long enough. So, in 2008 D. Vizgalov called marketing of the city the main tool for urban development and at the same time pointed to a comfortable living environment as one of the two main factors of this development, along with favorable conditions for economic activity [1, p. 22].

For the purpose of considering the comfort of the living environment from the standpoint of the concept of city marketing, it is necessary to clarify that now it is possible to talk about formation of the three approaches to the interpretation of marketing of territories, in particular to marketing of the city [2]. The first approach is subjective, or competitive, according to which the city is a subject located in competitive surroundings of the same subjects-cities. It is understood that cities compete with each other for all possible types of resources, first of all for investments and talented specialists for the most important spheres of activity. The main goal of marketing with this approach is a comprehensive increase in the competitiveness of the city.

In accordance with the second, the commodity, approach, the city is treated as a commodity that represents a certain value for current and potential consumers. Here the main

* Corresponding author: vmpolyakov@mail.ru 
goal is to get maximum benefit by the "sellers" of the city by fully meeting the needs of all "buyers".

Within the third approach, marketing is defined as an urban management tool. This approach can be called managerial. Among its features, first, the focus on the interest of all subjects (authorities, business, and local communities) in the development of the city can be identified. At the same time, all of them should conduct their activities on the principles of marketing. Secondly, none of the subjects can realize its interests without taking into account the interests of other entities. Thirdly, the present approach is applicable both to the solution of current urban problems, and to meet the challenges of prospective urban development. The result of marketing in this case is to increase the attractiveness of the city for:

- business - through improving the investment climate;

- visitors - through tourist attraction;

- residents - through the comfort of the living environment in the city.

In the period from 2006 to 2014-2015, some Russian experts have attempted to identify indicators (criteria) for the comfort of living. D. Vizgalov characterizes the living environment of the residents as comfortable in three aspects: spatial, psychological, and ecological [1, p. 22]. Other authors have directed efforts to form a set of new criteria for assessing comfort. In this case, the need to improve the comfort of the urban environment is often only declared. How to do it remains a problem, since only general recommendations were given and initial guidelines for further development of the problem defined.

We believe that, before taking actions related to the planning and development of directions for improving / developing the comfort of the living environment, it is advisable to assess the initial, basic level of the comfort. In other words, it is necessary to conduct its diagnostics and, on the basis of the data obtained, determine the directions and develop measures to further improve the comfort.

\section{Materials and methods}

Understanding the need to diagnose the level of comfort of the living environment marks a transition to a modern stage of consideration. In recent years, namely, from the second half of the 2010s, interest in assessing the comfort of the urban environment has increased, as evidenced by the conducted applied research.

So, A. Bagirova and co-authors proposed a methodology of a complex estimation of micro-districts of the city based on the opinions of residents and evaluation of their satisfaction with the living conditions in their areas [3]. We believe it is highly valuable that the research is based on the principle of obtaining the initial information from the users of the urban environment - the residents. At the same time, we do not agree with the interpretation of comfort in the living environment as a secondary indicator in the system of criteria for calculating the rating of the territory. This is a consequence of the goals of the researchers, namely, to receive ratings of individual areas of the city that means their comparative study. We consider the main issue to obtain information about the initial, basic conditions of the comfort environment in general, in order to further develop guidelines for development / improvement of comfort of the urban environment.

Another example is in 2017, under the aegis of the Ministry of Construction of Russia, the index of quality of the urban environment was developed [4]. It is difficult to recognize it as successful, because the proposed methodology, in our opinion, suffers from incorrectness, and the conclusions are rather an explanation of why the inhabitants of small towns leave for megacities, and from megacities - beyond Russia. We believe that the purpose of such developments should be to obtain data to achieve the main goal of marketing the city: to make sure that residents do not leave their cities! In the methodology, the same terms (security, comfort, environmental, identity and diversity, the modernity of the environment) 
are used in different sets of indicators, while their semantic meaning from the set to the set is radically different. For example, comfort in the group of indicators 1 "Housing and adjacent spaces" is interpreted as "the share of housing stock provided with the centralized services of heat, water, electricity, water disposal, \%", and in the group 2 "Landscaping and water spaces" - as "accessibility parks or arrangement of the natural landscape, \%". Further, the estimation of the individual indexes is made according to the state statistics (without involvement of the municipal!), the Ministry of Internal Affairs of Russia, according to the results of technical observations (GLONASS and so on), etc. At the same time, there are no assessments from the cities' residents, the business community and other groups of users of the urban environment. In addition, the comfort of the living environment is presented as only a particular indicator.

An interesting experience is the study of the comfort of living by the example of Russian mono-towns [5]. The fact that comfort is considered as one of the main factors of urban development can be attributed as merits of this study. Based on this assumption, a system of particular evaluation criteria is formed. The assessment itself is based on the results of a survey of citizens. This ensures the implementation of an important feedback principle. At the same time, we do not agree, firstly, with the fact that the comfort criteria system consists of only six enlarged indicators: economic attractiveness, affordability of housing, accessibility of social services, energy saving, natural environment, cultural and recreational activities.

Each of the indicators requires, in our opinion, detailing, especially since such a small object as a mono-city is being investigated. Working with these indicators, one can get only a generalized assessment of the comfort of the environment, missing many interesting and important details, and the assessments and conclusions themselves will be less meaningful and useful. As a consequence, the usefulness of recommendations for improving / developing the comfort of the city is diminishing. Secondly, the tasks to compare the level of comfort in a mono-town with the average level in the region are incomprehensible for researchers.

A review of Russian publications has shown that many authors consider comfort as a particular criterion of the quality of the urban environment. We insist that comfort is a system-forming concept, which should be studied using a set of concrete criteria. At the same time, it is important to observe the principle of a feedback, because only according to the results of surveys of the residents themselves the adequate estimates of the initial state of comfort of the environment can be obtained.

\section{Results}

The development of the approach to diagnosing the comfort of the urban environment from the positions of the city marketing management concept has been carried out in the following sequence:

1. Based on the generalization of domestic experience in the development of sets of criteria $[3 ; 5 ; 6 ; 7 ; 8 ; 9 ; 10 ; 11 ; 12 ; 13 ; 14,15,16,17]$, the enlarged criteria, sufficiently fully and consistently reflecting in the aggregate the state of comfort of the urban environment have been developed, such as:

A. The state of the city economy (socio-economic position);

B. Availability of work / education (jobs / places in educational institutions);

C. Accessibility of housing;

D. Quality and accessibility of goods and social and commercial services to the residents;

E. Degree of infrastructure development in a broad sense (business, social, transport, communications);

F. Security (including the social climate in the city); 
G. The state of the natural environment (ecology);

H. Conditions for cultural activities / recreation / creative activities of the residents.

2. A system of criteria clarifying the content of the points from $\mathrm{A}$ to $\mathrm{H}$ has been developed. The system reflects the following requirements to the comfort of the city environment [15]:

- Functional - these are direct requirements to the qualities, characteristics and ways of consumption and use;

- Social - these are the requirements mediated by the influence of the environment, in which the consumer is located. These can be different social strata to which it belongs or aspire to belong;

- Psychological - these are requirements mediated by the mood and emotions, which the product has to generate in order to provide a person with a stable state of mind.

These requirements are justified by the provisions of the managerial and commodity concepts of city marketing theory, according to which the city is treated as a commodity, and people (residents) as consumers. Consumers present requirements, specified above, to the city-commodity.

3. Intervals for assessment of each of the criteria are defined.

Functional requirements to the comfort of environment reflecting general conditions of living in the cities are specified with the following set of criteria.

1. General assessment of the living standards in the city. The intervals are:

- $\quad$ Living standards are low and continuing to decrease;

- $\quad$ Living standards are high and have trends to the continuing growth.

2. The general level of prices in the city. Intervals:

- $\quad$ Prices are perceived by the residents as high;

- $\quad$ Prices are perceived by the residents as acceptable (low).

3. The price for 1 square $\mathrm{m}$. of the primary housing. Intervals:

- $\quad$ High prices;

- Low prices.

4. The price for 1 square $\mathrm{m}$. of the secondary housing. Intervals:

- High prices;

- Low prices.

5. The prices for rental housing. Intervals:

- $\quad$ High prices;

- Low prices.

6. The price of land for individual construction. Intervals:

- $\quad$ High prices;

- Low prices.

7. Availability of mortgage. Intervals:

- Complicated procedure for obtaining a mortgage loan;

- Simplified procedure for obtaining a mortgage loan.

8. The quality of the housing stock. Intervals:

- $\quad$ The housing stock in the city is mostly dilapidated / emergency;

- The housing stock is mostly new / in a normal standing.

9. The quality of the communal services (provision of heat, water and electricity, and sewerage). Intervals: 
- The quality of the provided services is low;

- The quality of the provided services is high.

10. The quality of the food and long-use goods in the stores of the city. Intervals:

- $\quad$ The quality of food and goods is low;

- The quality of food and goods is high.

...

35. The quality of the tap water. Intervals:

- Low quality (the water is dirty with impurities, with a smell);

- High quality (the water is clean, free of odors).

36. Air quality and fumes. Intervals:

- Dirty air ("It is impossible to breath");

- Clean air ("easy to breath").

37. Noise level at the city streets. Intervals:

- A lot of noise;

- Quite streets / districts.

38. Greening of streets / yards. Intervals:

- There is no greening on the streets;

- Streets / yards are full of greening.

Functional requirements to the comfort environment reflecting the conditions of work and engagement in other kinds of activities in the cities are represented with the following set of criteria:

1. The level of salaries and other incomes in the city. Intervals:

- $\quad$ Low / lower than the national /regional average;

- High / higher that the national / regional average.

2. Unemployment level in the city. Intervals:

- High / higher than national average;

- Low / lower than the national average.

3. Availability of jobs. Intervals:

- It is difficult to find an appropriate job in the city (in accordance with the specialty or the interest);

- It is easy to find an appropriate job in the city (in accordance with the specialty or the interests).

4. The price for training in the educational institutions of the city. Intervals:

- High price;

- Low price.

5. Conditions for business in the city. Intervals:

- Many obstacles (“difficult” business);

- Few obstacles / no obstacles ("easy" business).

6. Distance of residence from the place of work. Intervals:

- The place of work is located far from the residence;

- The place of work is located in "walking" distance from the place of residence.

7. The price for 1 square $\mathrm{m}$. of the commercial property. Intervals:

- High price; 
- Low price.

8. The rental prices for office, trade, industrial and other commercial premises. Intervals:

- High prices;

- Low prices.

9. The price of land in the city for residential / non-residential construction. Intervals:

- High price;

- Low price.

10. The terms of registration (opening) a business. Intervals:

- $\quad$ It is difficult to open a business;

- It is easy to open a business.

...

16. Payment of the sick leaves to employees. Intervals:

- Minimum;

- Maximum.

17. Payment for journey to the place of rest / treatment by the employer. Intervals:

- $\quad$ The journey is not paid;

- The journey is paid.

18. Payment for training and professional development of employees by the employer. Intervals:

- Training and professional development is not paid;

- Training and professional development is paid.

19. Frequency of the public transportation in the rush hours. Intervals:

- Public transportation in the rush hours works intermittently;

- Public transportation in the rush hours works regularly, without breaks.

20. Possibility to work remotely, from home. Intervals:

- It is impossible to work remotely in the city;

- The city has all conditions for the remote work.

21. Development of the on-line services (applications). Intervals:

- The services are not developed;

- The services are developed.

22. The presence of the organized criminal groups in the city. Intervals:

- There are several criminal groups in the city, including these ones from other cities;

- There is no organized criminality in the city.

23. The state of corruption in all spheres of activity. Intervals:

- It is impossible to do anything without bribes;

- "All are fair" / "everything is transparent".

24. Development of the shadow business in the city. Intervals:

- All business is in the shadow;

- All business is "white".

25. The degree of development of the "green" technologies / "green" companies in the city. Intervals:

- The residents of the city do not know what it is; 
- Most of the companies that work in the city are "green" companies.

26. Remuneration of workers for offers, innovations and know-how in the workplaces. Intervals:

- There is no remuneration;

- There is remuneration.

27. Working conditions for the people of "free" professions ("creative class") in the city. Intervals:

- There are no such people;

- People of "free" professions can always find engagements.

The functional requirements to the comfort of environment reflecting conditions for rest and creative activities in the cities are represented with the following set of criteria:

1. The presence of theaters, cinema theaters and concert halls in the city/ Intervals:

- There are no such institutions in the city;

- There are all kinds of theaters / cinema theaters / concert halls in the city.

2. The average price for a ticket to the theater, cinema theater and concert hall. Intervals:

- High price;

- Low price.

3. Tours of national / global stars in the city. Intervals:

- $\quad$ They never come;

- $\quad$ They permanently (Often) come.

4. Holding of local, national, international festivals, exhibitions, fairs and other cultural and business events. Intervals:

- $\quad$ They never take place;

- They often (always) take place.

5. Availability of services of sport sections, fitness clubs, gyms, etc. Intervals:

- $\quad$ There is nothing of that in the city;

- There is a wide range of any services in the city.

6. The price for sports in the city. Intervals:

- High price;

- Low price.

7. Availability of public libraries. Intervals:

- There are no libraries;

- There is a library network in the city.

8. Availability of on-line access to the library collections. Intervals:

- $\quad$ There is no on-line access;

- There is on-line access.

9. Organization of the city clubs' activities. Intervals:

- It is impossible to organize a club;

- It is easy to organize any club, without additional obstacles.

10. Development of the sphere of hospitality in the city (hotels, public catering). Intervals:

- The sphere of hospitality is not developed; 
- The sphere of hospitality is developed.

11. The average price for one night in the city hotels. Intervals:

- High price;

- Low price.

12. The quality of service in hotels. Intervals:

- $\quad$ Low quality of service;

- High quality of service.

13. The size of the average check in the city restaurants / cafes per person. Intervals:

- High;

- Low.

14. The quality of cuisine in the city restaurants / cafes. Intervals:

- $\quad$ Low quality of cuisine;

- High quality of cuisine.

15. Availability of the entertainment facilities in the city (night clubs, discos, saunas, bowling, billiards, etc. Intervals:

- $\quad$ There are no such facilities in the city;

- There are enough such facilities in the city.

16. Average price for one visit to the entertaining facility. Intervals:

- High price;

- Low price.

17. Availability of the amusement park (parks) in the city and their accessibility. Intervals:

- $\quad$ There is no amusement park in the city;

- There is at least one amusement park in the city, and price for a visit is moderate.

18. Availability and conditions of the forest park areas. Intervals:

- $\quad$ There are no forest park areas in the city;

- There are forest park areas in the city.

19. Attitude to the change of the natural environment. Intervals:

- $\quad$ The urban space worsens the environment;

- The urban space harmonically "fits" into the natural landscape.

20. Availability / accessibility "the week-end program" for the residents. Intervals:

- $\quad$ Residents spend week-ends at home;

- There is a lot of different cultural, entertainment, sport and other events in the city during the week-ends.

Social and psychological demands of the city residents for the comfortable living environment are revealed in a similar way. Complex satisfaction of these demands gives, in the end, the residents a sense of comfort of their living environment.

\section{Conclusion}

The proposed approach to diagnosing the comfort of the urban living environment is characterized by the following:

1) the comfort of the environment that is not a particular indicator, but a backbone one, which determines the level (degree) of the urban development as a whole; 
2) the diagnostics is based on the data obtained through a survey of residents, therefore, using the principle of feedback;

3) the suggested approach takes into account and details the experience of domestic studies;

4) the approach is based on the provisions of the managerial and commodity concepts of the city marketing theory.

\section{References}

1. D. V. Vizgalov, City marketing (Institute of City Economics, Moscow, 2008)

2. N. V. Polyakova, V. Ye. Zaleshin, Marketing of territories (BSU Publishing, Irkuts, 2017)

3. A. P. Bagirova, O. V. Notman, J. Veresh, Economy of the Region, 4, 1138-1150 (2017)

4. Minsitry of Civil Engineering, Urban Quality Index (http://индекс-городов.рф, 2018)

5. T. A. Pershina, M. P. Gogoleva, Regional Economy and Management, 2(46) (2016)

6. A. P. Pankrukhinh, Marketing of territories (Piter, St.Petersburg, 2006)

7. D. V. Vizgalovb, City branding (Institute of City Economics, Moscow, 2011)

8. M. L. Bacherikova, I. M. PRomanova, Regional Economy and Management, 1(49) (2017)

9. A. A. Kuklin, M. S. Pecherkina, A. N. Tyrysin, A. A. Surina, Economy of the Region, 4, 1030-1043 (2017))

10. Ye. R. Meteleva, Baikal Research Journal, 1 (2017)

11. I. Yu. Shvets, Baikal Research Journal, 4 (2016)

12. A. V. Shishkin, T. V. Murtuzaliyeva, B. I. Pogorilyak, Practical Marketing, 10, 14-22 (2017)

13. A. V. Bogoviz, S. V. Lobova, A. N. Alekseev, I. A. Koryagina, T. V. Aleksashina, Advances in Intelligent Systems and Computing, 622, 609-616 (2018)

14. D. O. Yeliseev, Regional Economy and Management, 4(52) (2017)

15. S. V. Zakharov, Regional Economy and Management, 1(49) (2017)

16. A. V. Bogoviz, Y. V. Ragulina, N. V. Sirotkina, Advances in Intelligent Systems and Computing, 622, 597-602 (2018)

17. N. V. Polyakova, V. Ye. Zaleshin, Baikal Research Journal, 1 (2016) 